\title{
EFFECT OF ETHANOLIC EXTRACT OF OLIVE LEAVES ON BLOOD GLUCOSE AND CHOLESTEROL LEVELS IN DIABETIC RABBITS
}

\section{F. AL-KAZAK ${ }^{*}$, A. AL-ABD ${ }^{* *}$ and T. KANBAR ${ }^{* * *}$.}

* Department of Pharmacology and Toxicology, Faculty of Veterinary Medicine, Al Baath University, Hama, Syria.

** Department of Physiology, Faculty of Veterinary Medicine Al Baath University, Hama, Syria.

*** Department of Pharmacology and Toxicology, Faculty of Veterinary Medicine, Al Baath University, Hama, Syria.

Received at:13/2/2012

Accepted: 7/3/2012

\section{ABSTRACT}

The present study aims to investigate the effect of ethanolic extract of Olive leaves (Olea europaea L.) on blood glucose and cholesterol levels in diabetic rabbits. Diabetes was induced in rabbits by intraperitoneal injection of alloxan. The experiment was carried out on 36 rabbits of both sexes weighing between (2100$2500 \mathrm{gm})$. The experimental animals were divided into 3 groups, each group consisting of 12 animals. The first group was left as control, while the second and third groups, they were rendered diabetic by intraperitoneal injection of alloxan (175 mg/kg b.wt.). The second group was left as diabetic control, while the third was treated with the ethanolic extract of Olive leaves in a dose of 500 $\mathrm{mg} / \mathrm{kg}$ b.wt. orally/ day for 4 weeks. Blood samples were collected weekly till the end of the experiment from the heart for determination of glucose and cholesterol levels. The results obtained showed that oral administration of Olive leaves ethanolic extract significantly decreased the high blood glucose and cholesterol levels of the treated diabetic rabbits, as compared to the diabetic control group. In conclusion, Olive leaves of ethanolic extract produces antidiabetic and hypocholesterol levels in alloxan-diabetic rabbits and it may be beneficial to help patients who suffer from diabetes mellitus.

\section{تأثير الخلاصة الإيثانولية لأوراق الزيتون على مستوى السكر والكوليسترول الكلي في الام عند الأرانب المصابة بداء السكري العيكي والكري \\ فراس القزق ، أسعد العبد ، طلة قنبر}

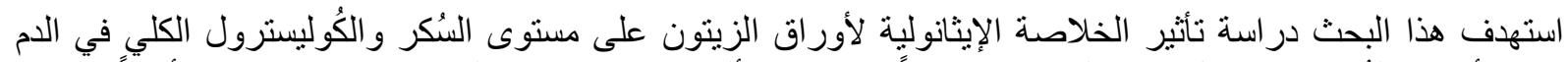

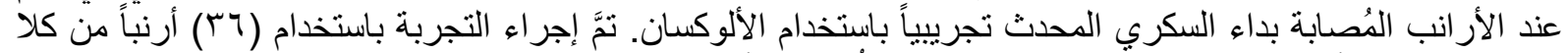

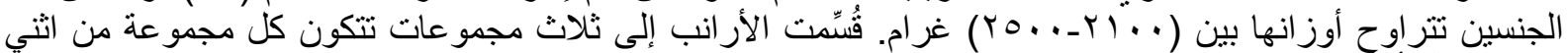

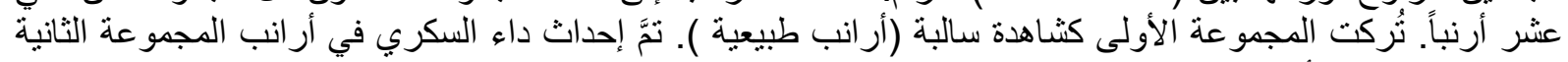

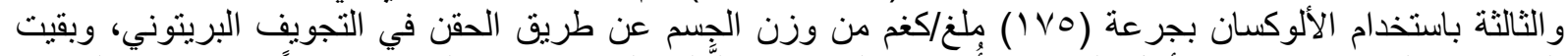

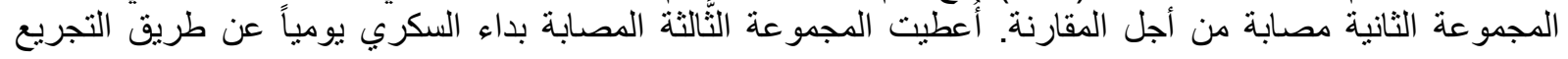




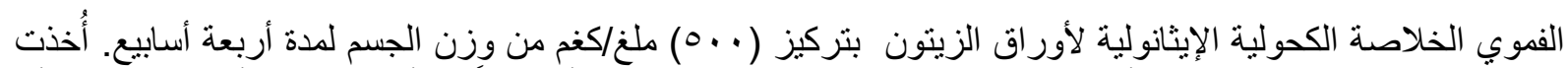

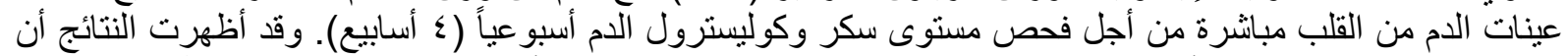

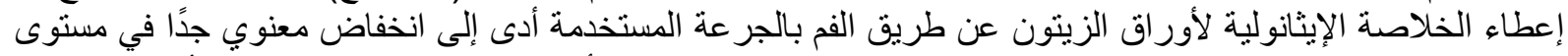

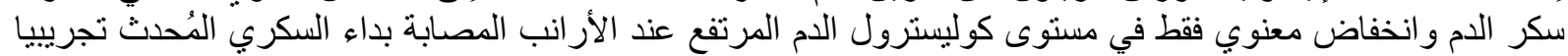
بالألوكسان.

\section{INTRODUCTION}

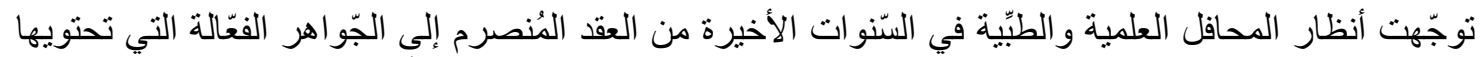

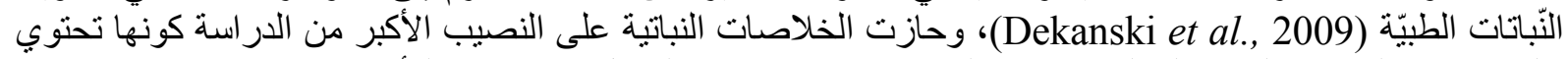

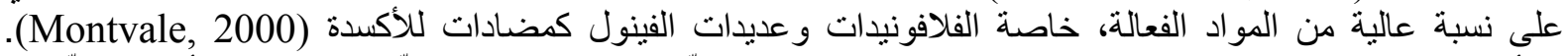

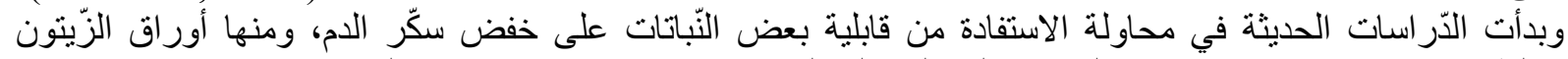

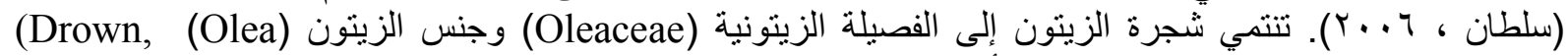

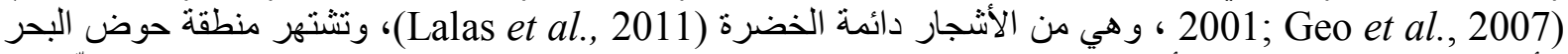

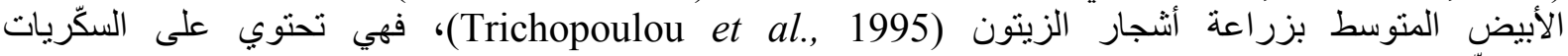

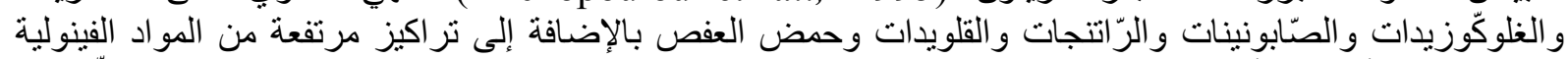

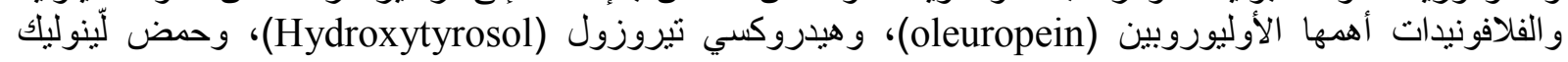

.(Briante et al., 2002; Omar, 2010) (Oleanolic acid)

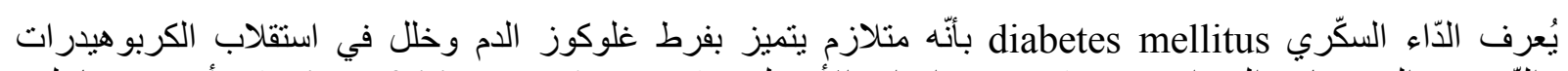

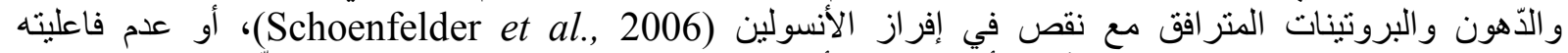

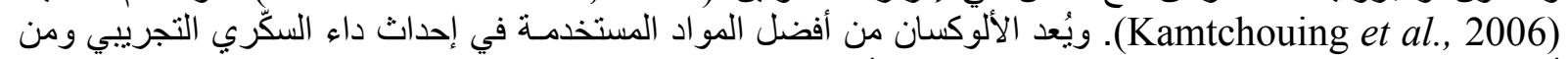

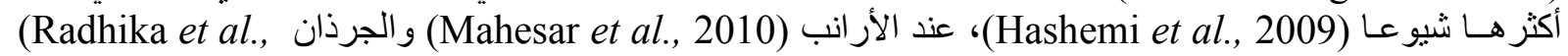

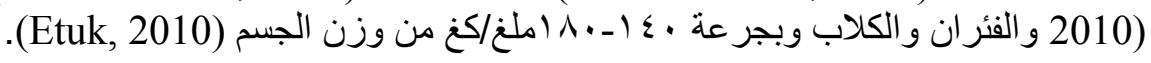

لقد استُخدم شجرة الزيتون ولعدة قرون مضت (الزيت والأوراق) في مجال الطب الثعبي كمادة مخفضة للسكر وللحر ارة (الزبيدى ، 997 ( ))، وضغط ولغدة الدون وكموسعة للأوعية الدموية (Cheij, 1984).

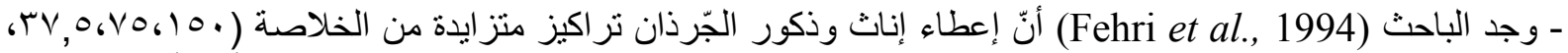

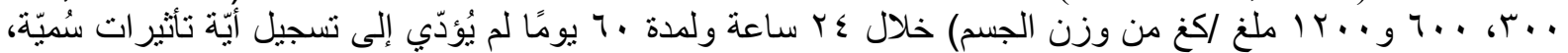

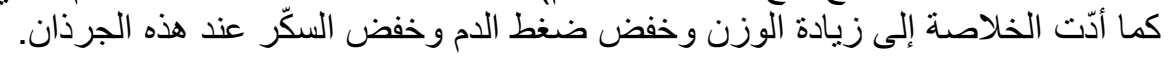

ـ و واستخدم الباحث (Khudiar, 200) الخلاصة المائية لأوراق الزيتون في خفض مستوى الكوليسترول الكلي و الدهون

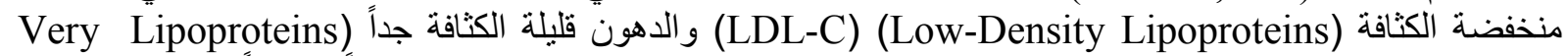
(VLDL-C) (Low-Density

الاصابة بالتصلب العصيدي.

- مو أنثتت در اسة الباحث (Benavente-Garcia et al., 2000) تأثير الفينو لات كمضاد للأكسدة وكخافض لغلوكوز الدمام

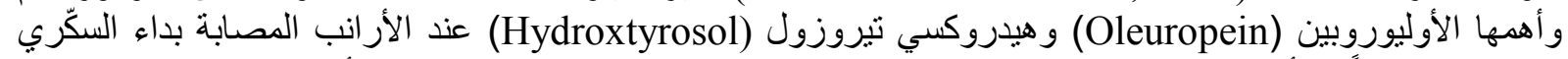

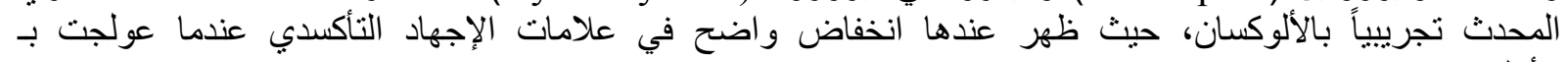

الأوليوروبين.

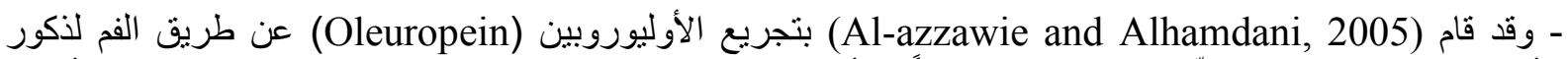

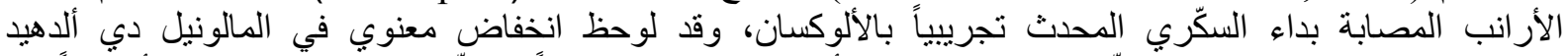
(Malondialdehyde)

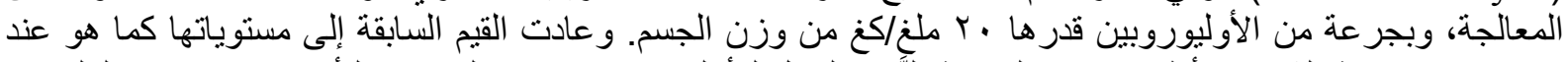

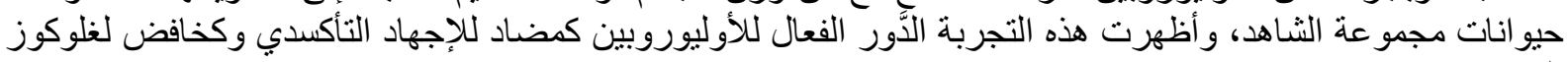
الدم.

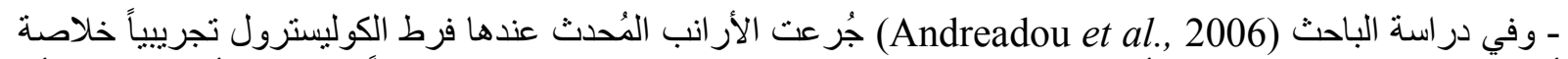

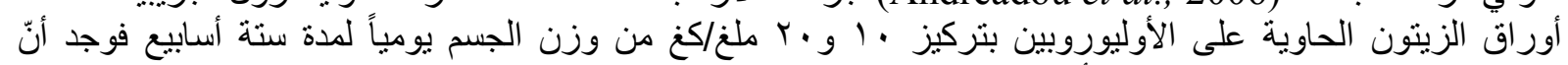

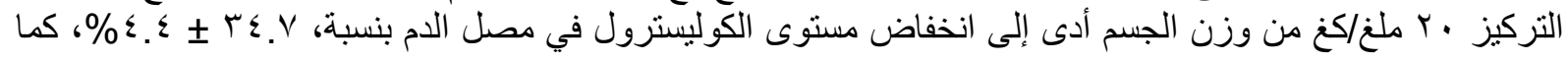




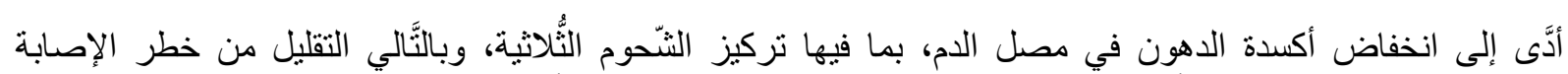

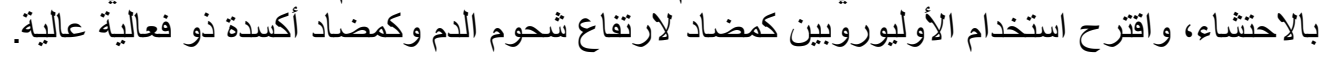

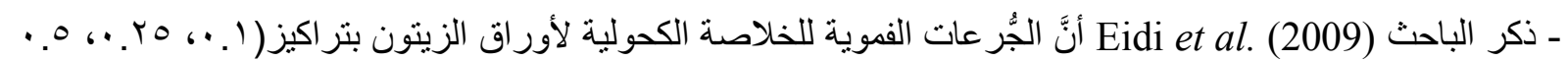

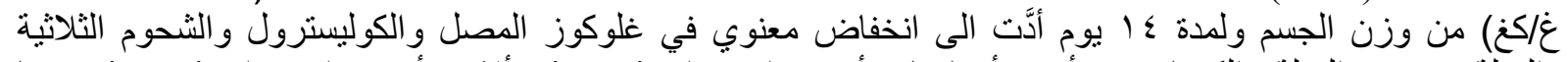

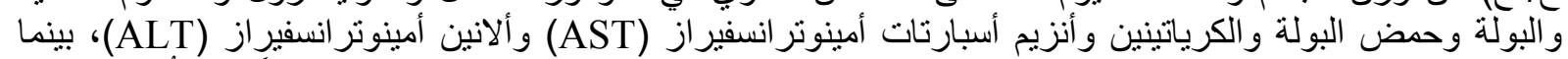

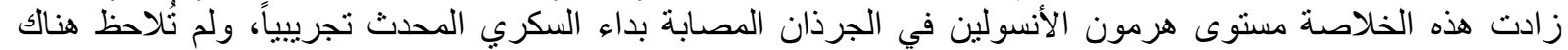

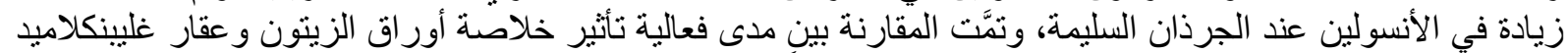

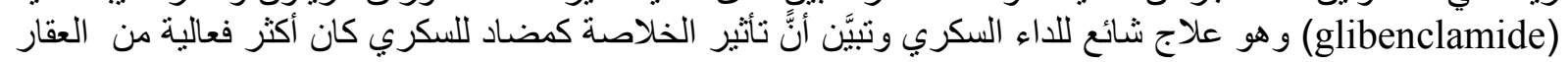

السابق الذكر.

\section{هدف البحث \\ OBJECTIVE OF THE STUDY}

استهدف هذا البحث دراسة تأثثر الخلاصة الإيثانولية لأوراق الزيتون على مستوى السكّر والكوليسترول الكلي في الدم

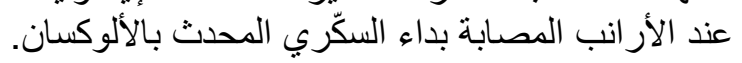

\section{المواد وطرائق البحث \\ MATERIALS and METHODS}

أولاً: تحضير الخلاصة النباتية الكحولية الإيثانولية لأوراق الزينتون:

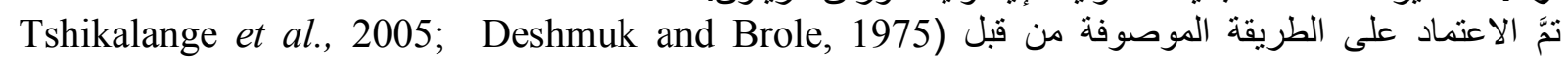

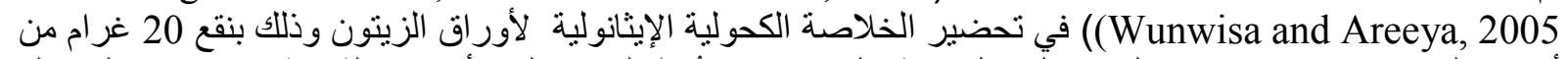

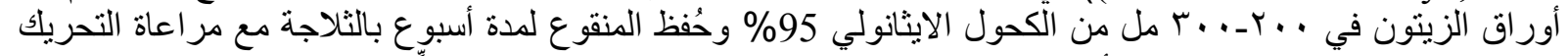

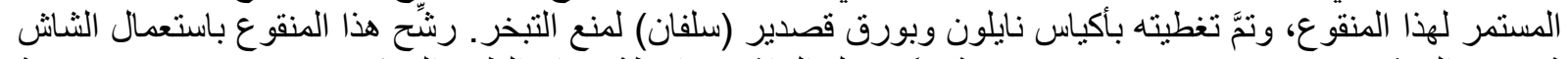

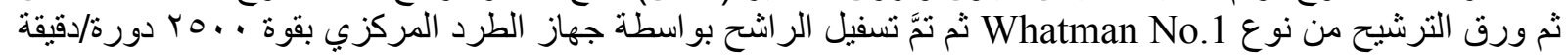

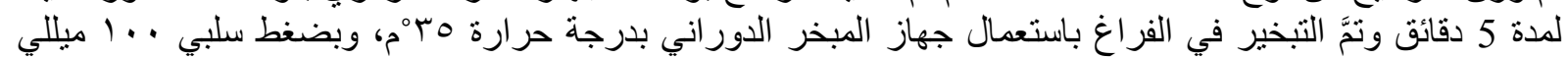

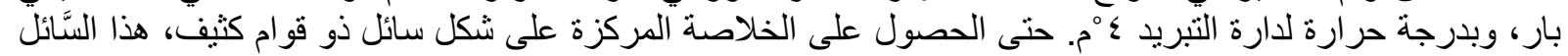

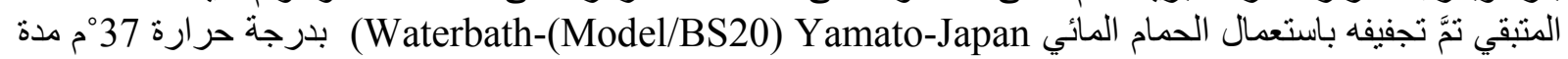

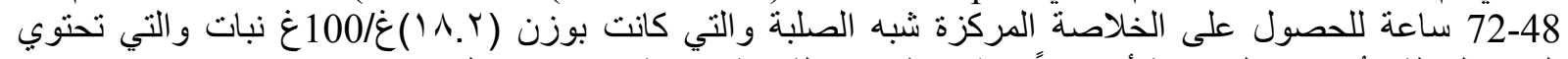

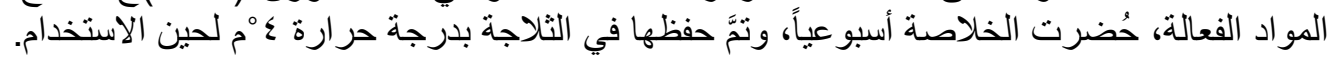

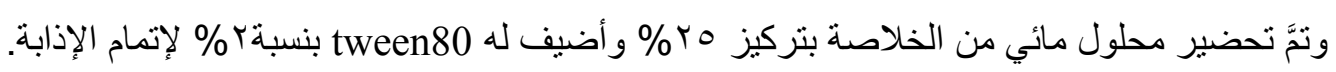

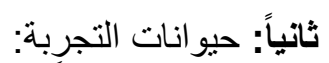

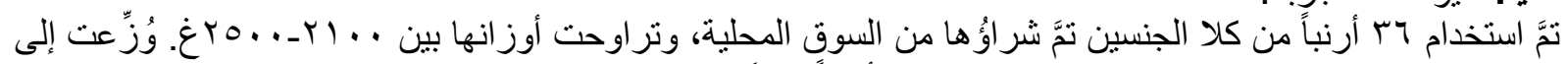

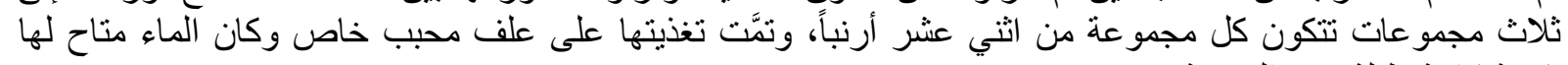
بكمية كافية طيلة فترة التجربة.

ثالثا: إحداث داء السكري في الأر انب بالألوكسان:

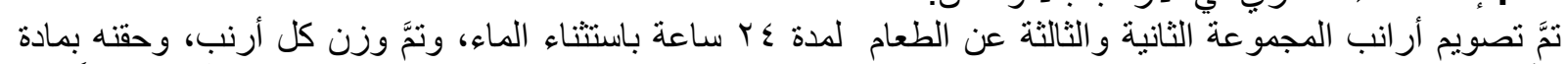

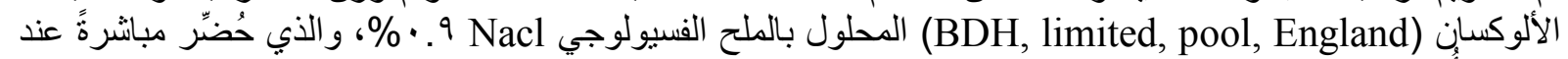

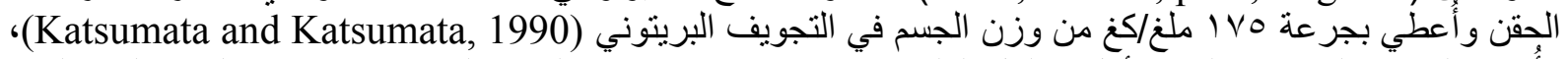

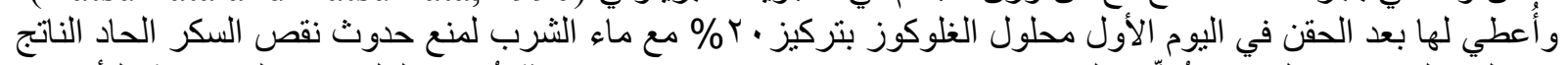

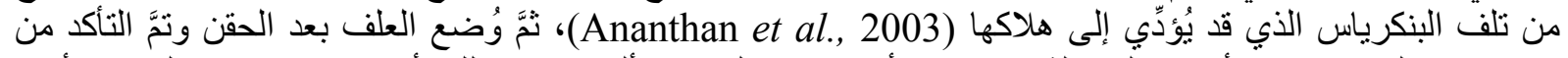

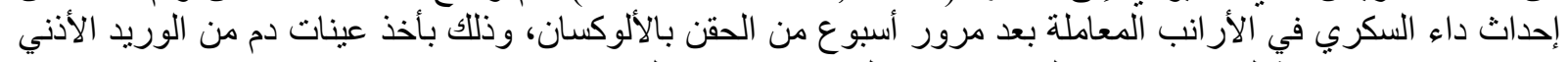

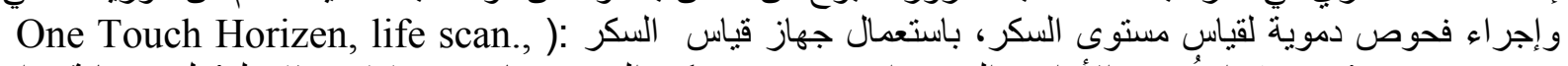
الكئ (USA sensor

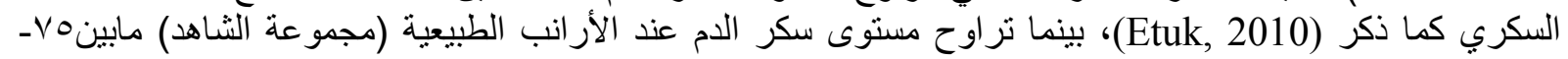

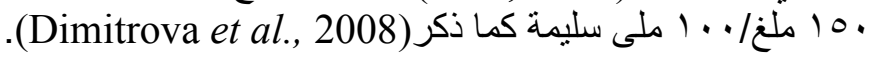

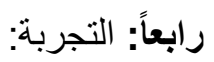




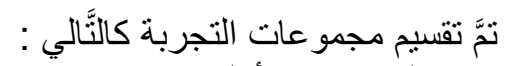
1 ـ المجموعة الأولى: مجمو عة شَاهدة (ضابط سلبي).

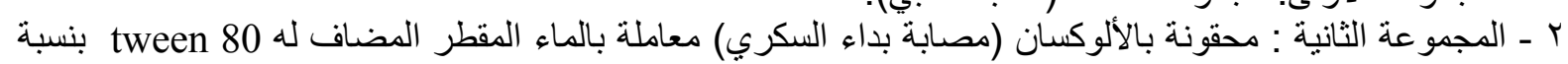

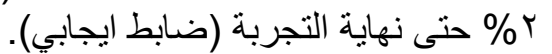

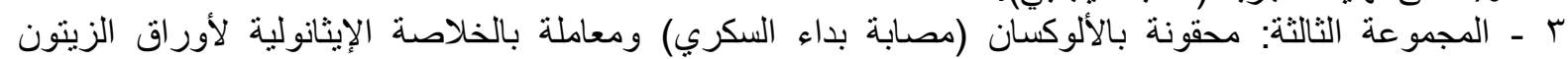

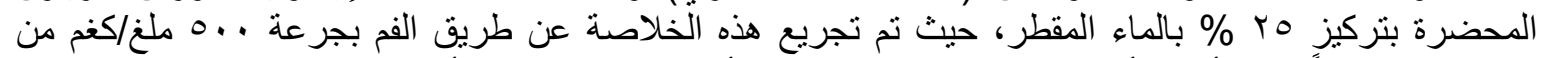

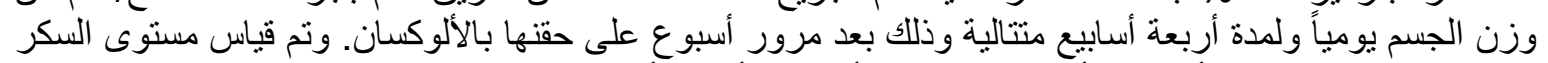

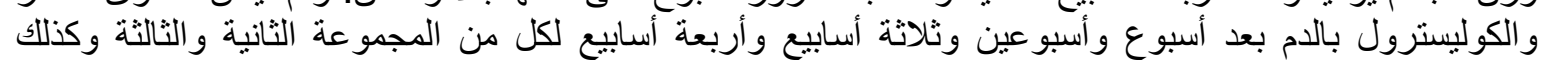

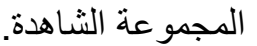

خامساً: التحليل الإحصائي:

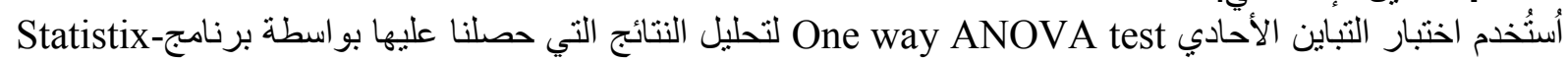

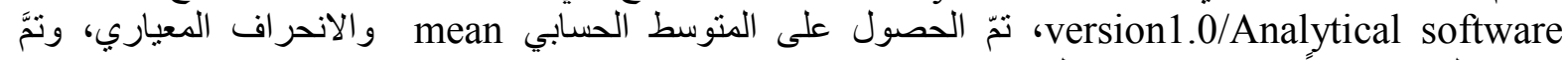
احتساب الفرق معنوياً عند مسنوى احتمال (p<0.05).

\section{النتائج \\ RESULTS}

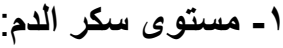

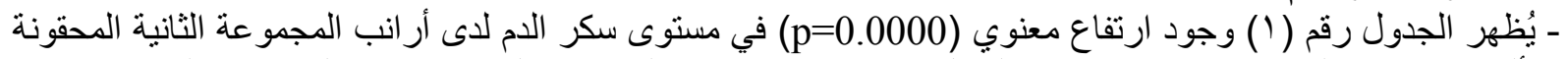

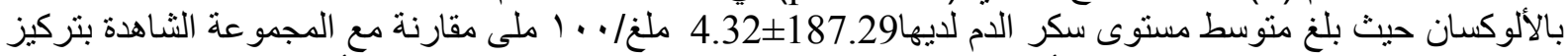

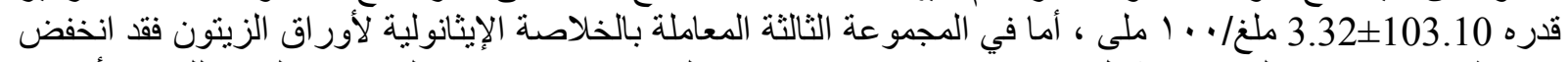

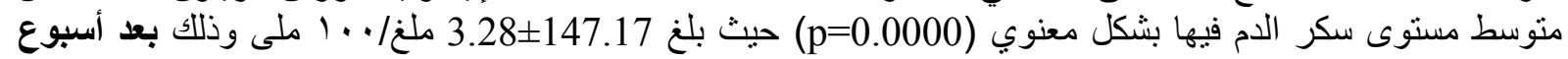
من المعاملة بالخلاصة الإيثانولية.

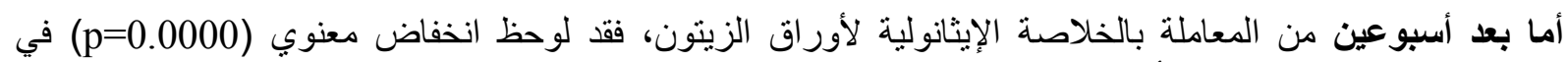

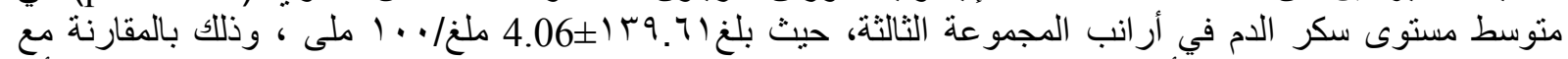

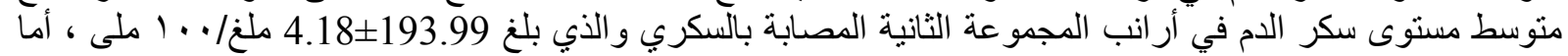

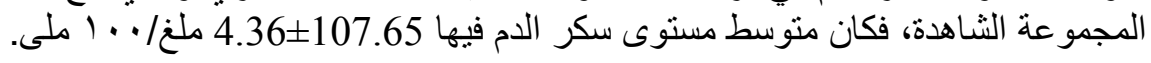

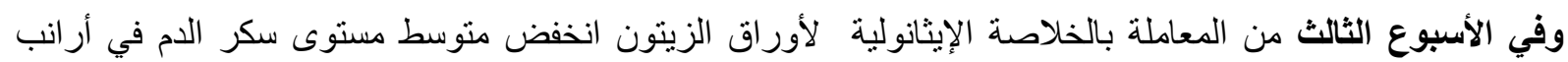

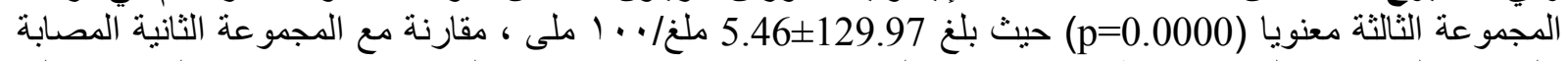

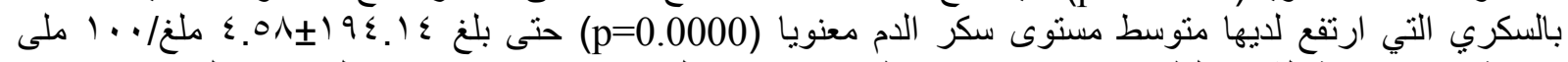

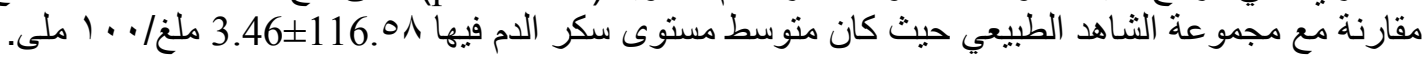

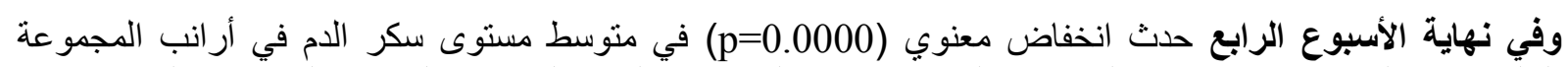

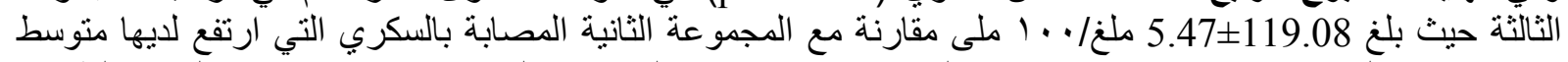

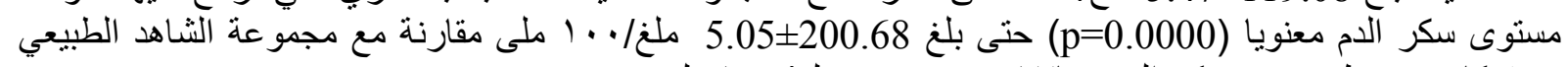

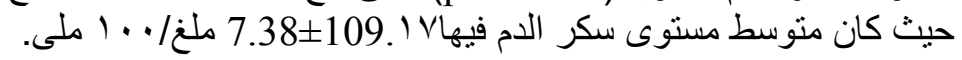

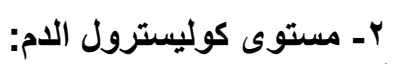

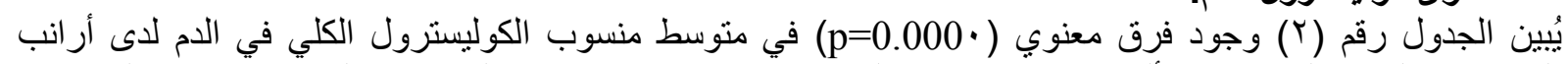

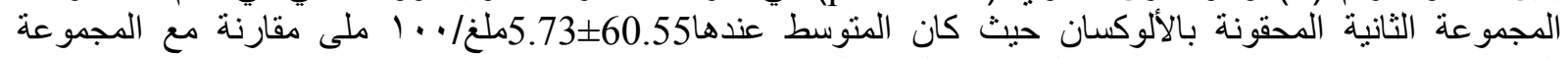

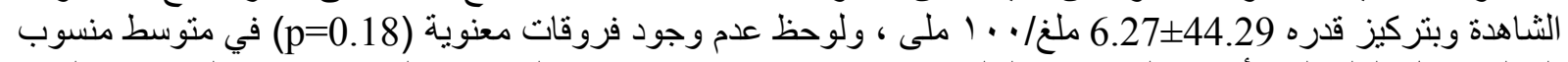

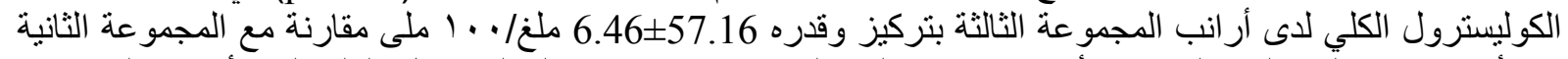

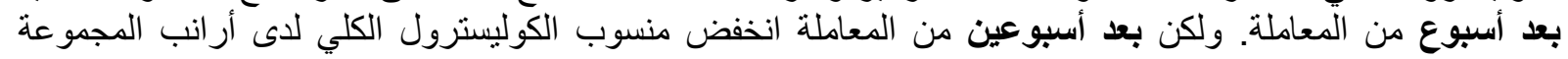

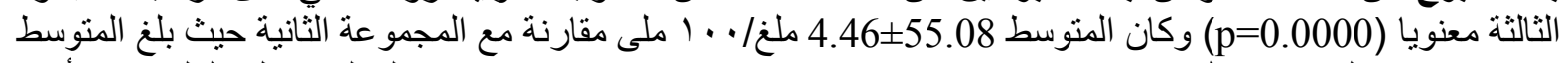

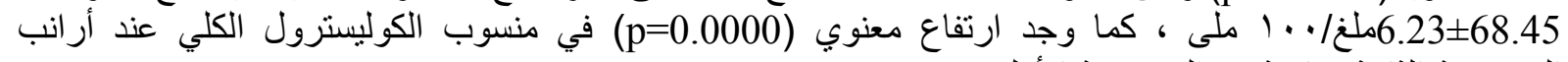
المجمو عة الثانية مقارنة مع المجموعة الأولى.

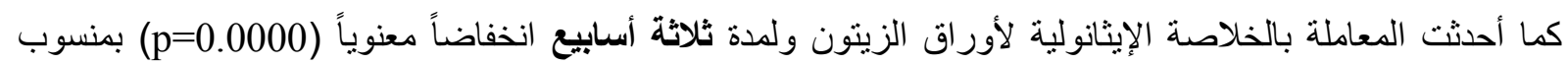

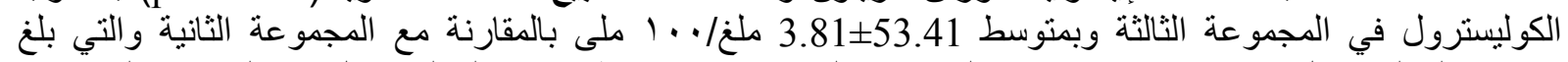

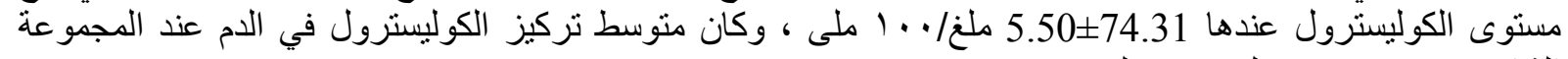

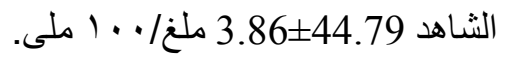




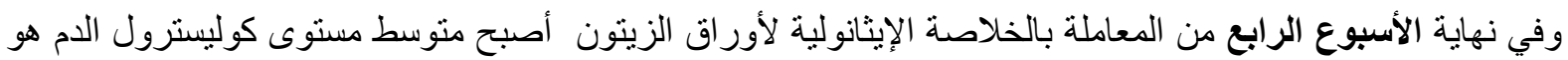

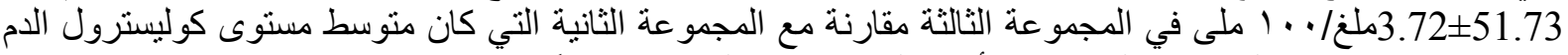

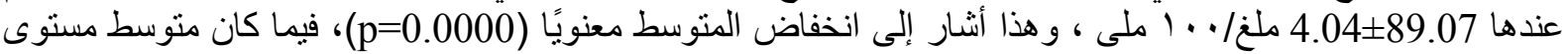
الكوليسترول في المجمو عة الثناهد

\begin{tabular}{|c|c|c|c|}
\hline المجموعة الثمالثة بالثة: مصابة الإيثانولية بالسكرية & 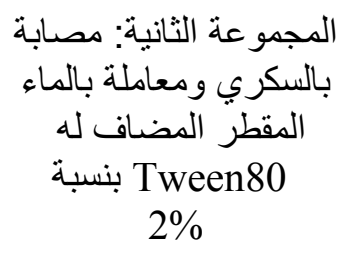 & (الثجاهد عة الطبيعي): & \\
\hline $\mathrm{b}_{3.28 \pm 147.17}$ & ${ }^{\mathrm{a}} 4.32 \pm 187.29$ & ${ }^{c} 3.32 \pm 103.10$ & بعد أسبوع \\
\hline $\mathrm{b}_{4.06 \pm 139.61}$ & a $4.18 \pm 193.99$ & ${ }^{\mathrm{c}} 4.36 \pm 107.65$ & بعد أسبو عين \\
\hline $\mathrm{b}_{5.46 \pm 129.97}$ & ${ }^{\mathrm{a}} 4.58 \pm 194.1 \leq$ & ${ }^{c} 3.46 \pm 116.58$ & بعد ثلاث أسابيع \\
\hline${ }^{b} 5.47 \pm 119.08$ & ${ }^{\mathrm{a}} 5.05 \pm 200.68$ & ${ }^{\mathrm{c}} 7.38 \pm 109.1 \mathrm{~V}$ & بعد أربع أسـابيع \\
\hline${ }^{b} 12.16 \pm 133.96$ & ${ }^{\mathrm{a}} 5.46 \pm 194.03$ & ${ }^{c} 5.59 \pm 109.12$ & المتوسط الحسابي \\
\hline
\end{tabular}

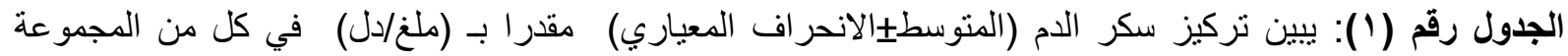

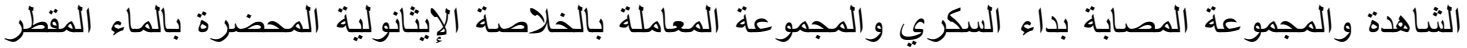

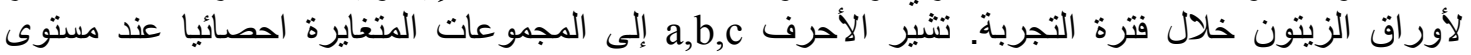

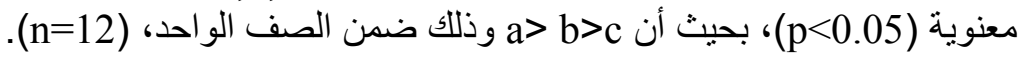

\begin{tabular}{|c|c|c|c|}
\hline 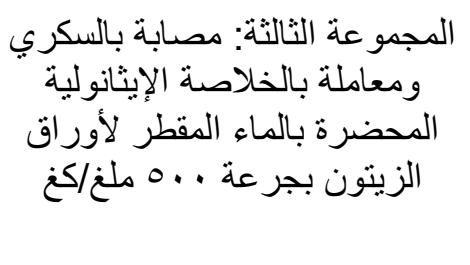 & 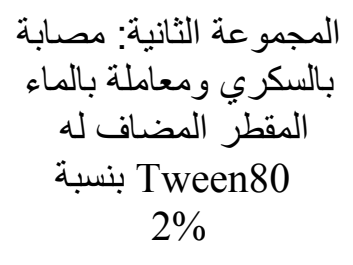 & (الثاهد الطبيعي) الأولى: & \\
\hline a $6.46 \pm 57.16$ & ${ }^{\mathrm{a}} 5.73 \pm 60.55$ & ${ }^{b} 6.27 \pm 44.29$ & بعد أسبوع \\
\hline${ }^{b} 4.46 \pm 55.08$ & ${ }^{\mathrm{a}} 6.23 \pm 68.45$ & ${ }^{c} 7.34 \pm 49.39$ & بعد أسبو عين \\
\hline $\mathrm{b}_{3.81 \pm 53.41}$ & ${ }^{\mathrm{a}} 5.50 \pm 74.31$ & ${ }^{c} 3.86 \pm 44.79$ & بعد ثلاث أسابيع \\
\hline $\mathrm{b}_{3.72 \pm 51.73}$ & ${ }^{\mathrm{a}} 4.04 \pm 89.07$ & ${ }^{c} 3.77 \pm 48.92$ & بعد أربع أسـابيع \\
\hline${ }^{b} 2.32 \pm 54.35$ & ${ }^{\mathrm{a}} 12.05 \pm 73.09$ & ${ }^{c} 2.67 \pm 46.85$ & المتوسط الحسابي \\
\hline
\end{tabular}

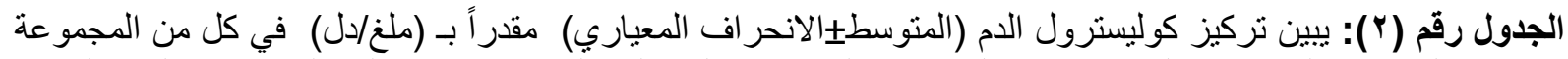

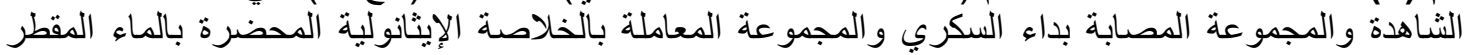

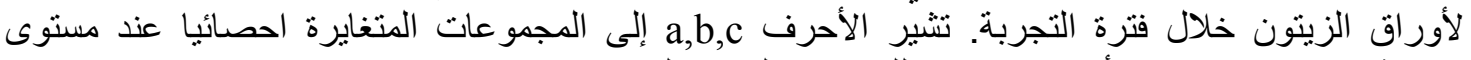

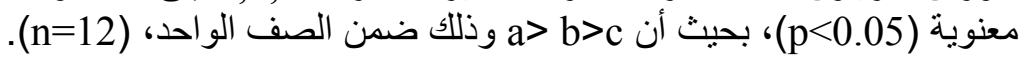

\section{المناقثـة \\ DISCUSSION}

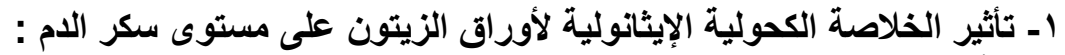

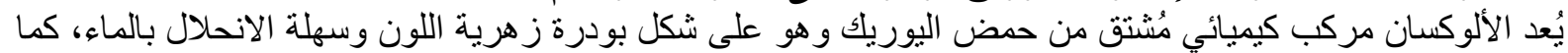

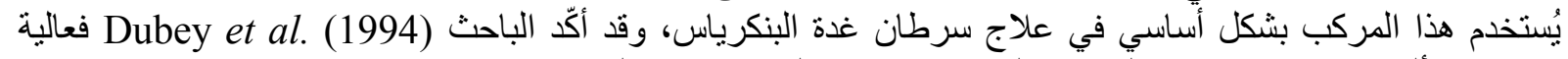

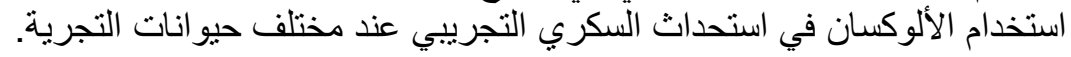


يُيبين الجدول رقم (1) ارتفاع في منسوب سكر الدم في المجموعة الثانية (مجموعة الألوكسان) بعد أسبوع من حقن

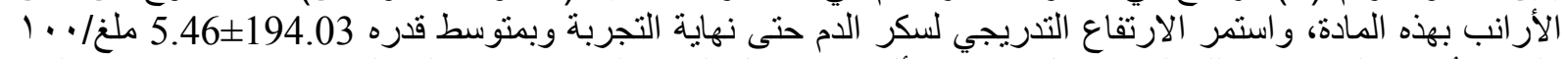

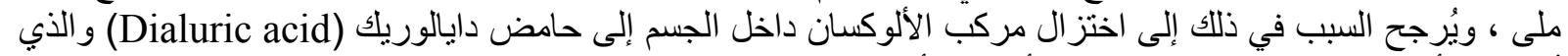

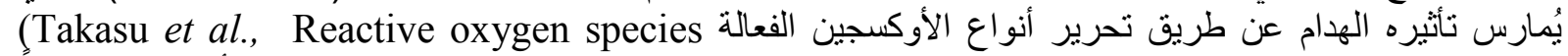

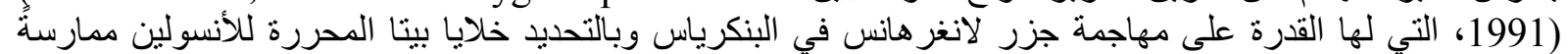

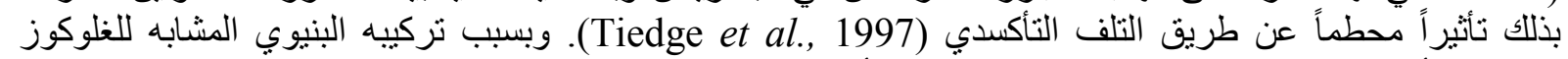

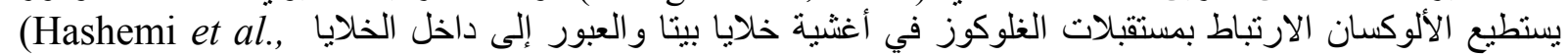

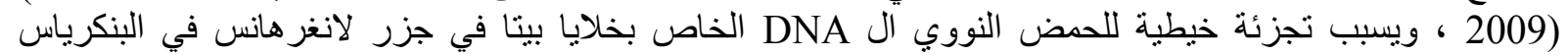

.(Szkudelski, 2001; Park et al., 1995; Okamoto, 1985)

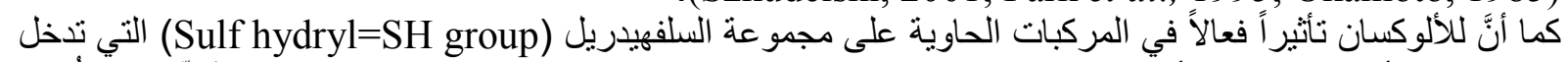

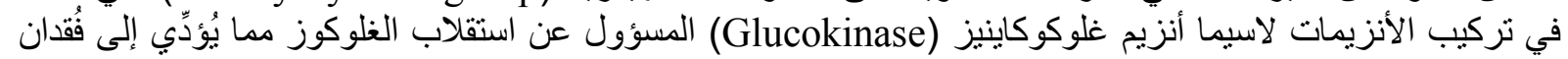
فعاليته (Lenzen et al., 1992).

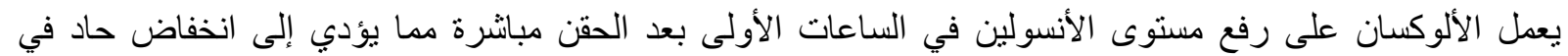

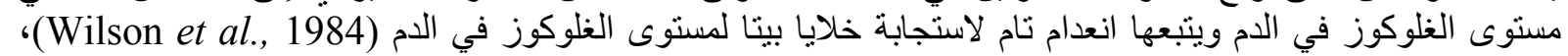

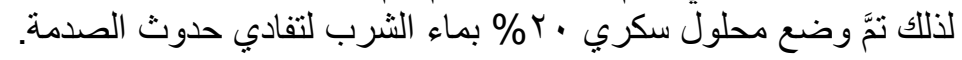

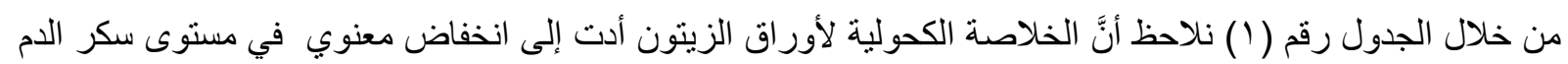

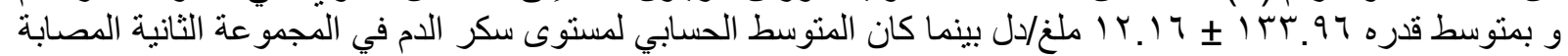

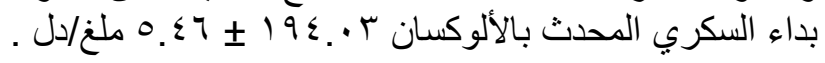

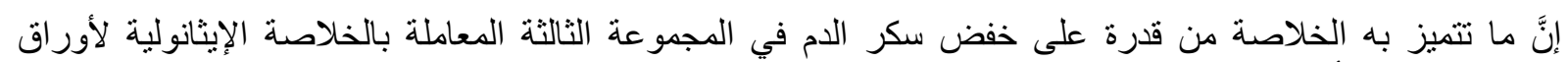

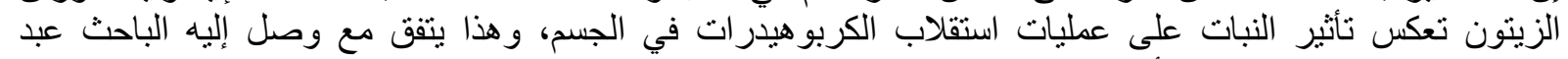

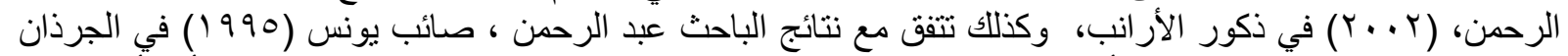

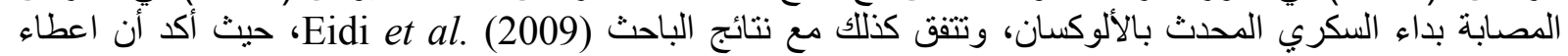

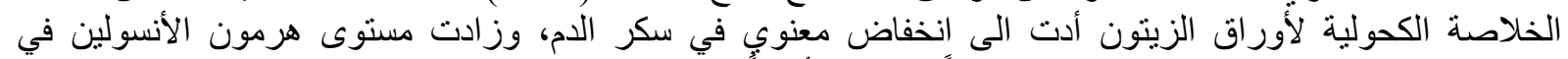

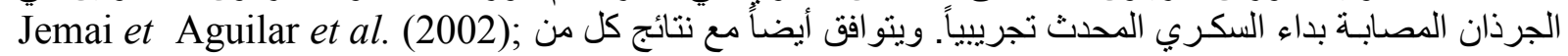
.al. (2009); Alarcon- Verspohl (2002)

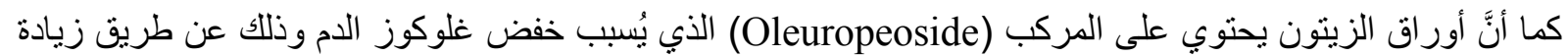

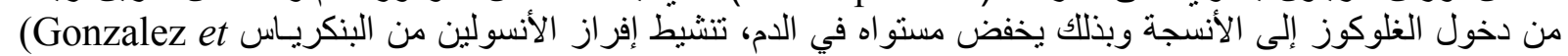

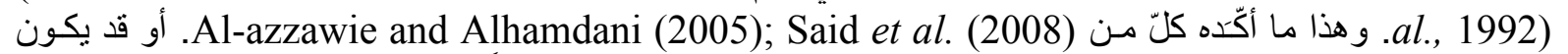
السبب وراء خفض سكر الدم عند الأر انب المصابة بداء السكري المحدث تجريبياً هو مـا تحتويسه الخلاصــة من نسبـة

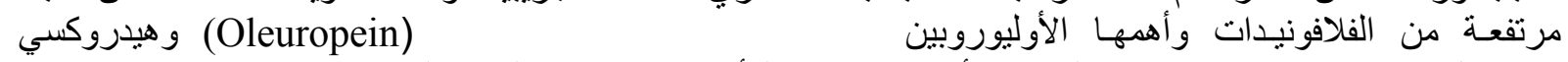

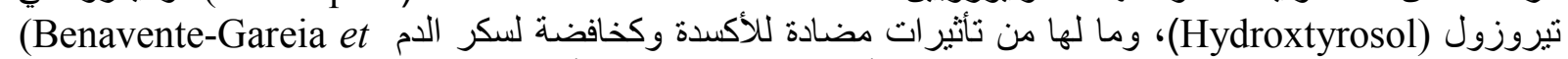
(al., 2000)

.(Satoa et al., 2007)

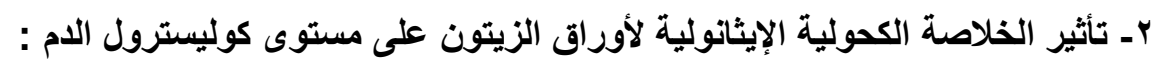

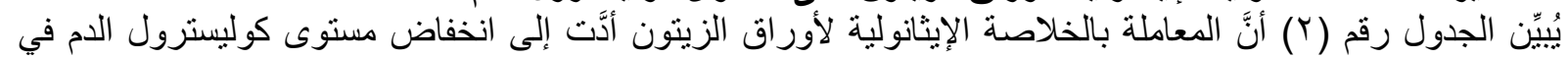

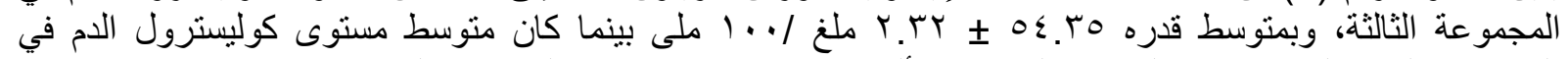

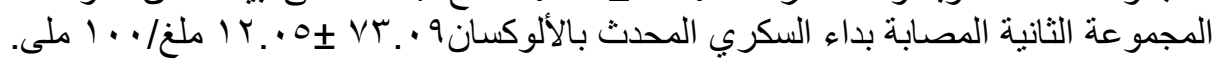

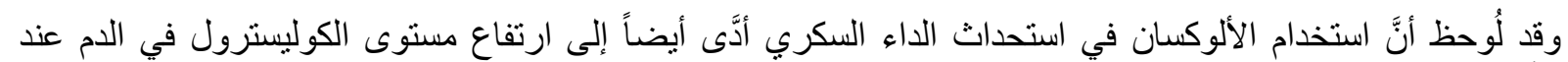

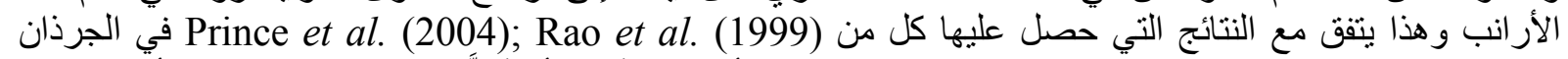

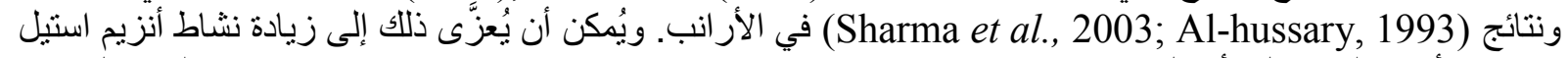

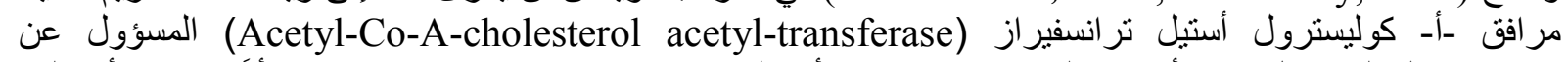

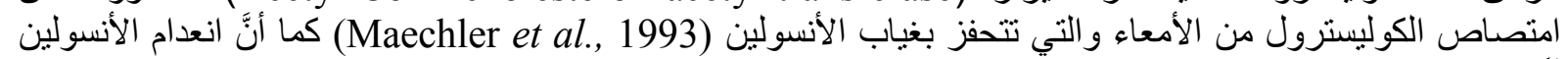

أدَّى إلى زيادة مستوى الكوليسترول من الأيعاء في الَّم (Lenich et al., 1990).

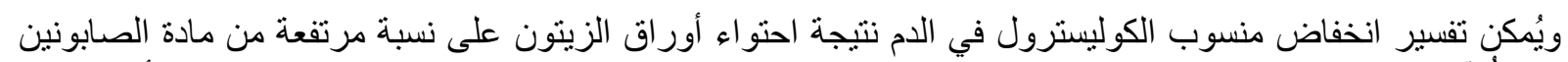

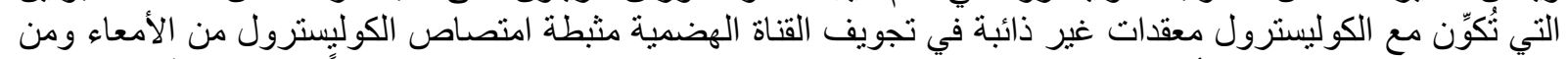

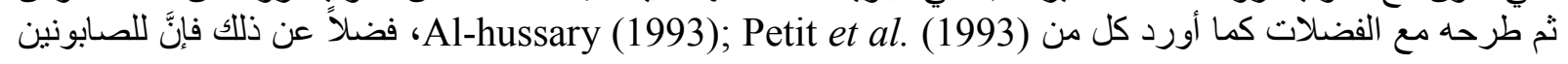


القدرة على الالتصاق مع أملاح الصَّفر اء و الثَحوم المتعادلة في الأمعاء وتثثيط امتصاصها ومن ثم خفض مستواه محفزاً الكبد لتحويل الكوليسترول إلى أحماض الفئل صفر اوية (Sauvaire et al., 1996).

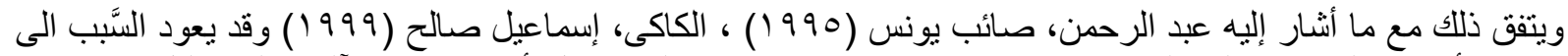

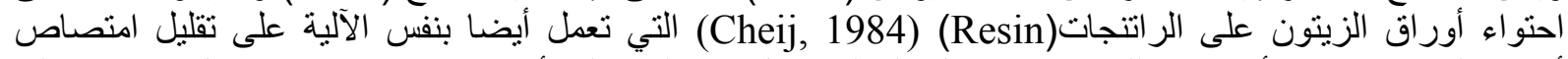

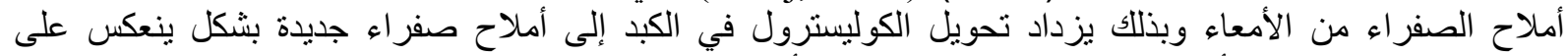

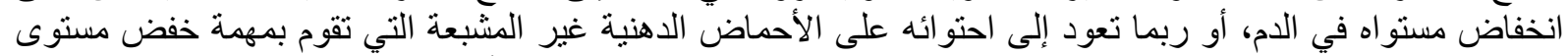

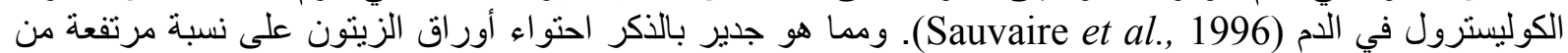

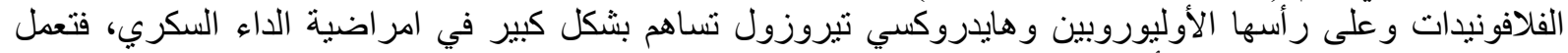

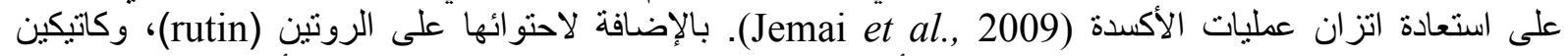

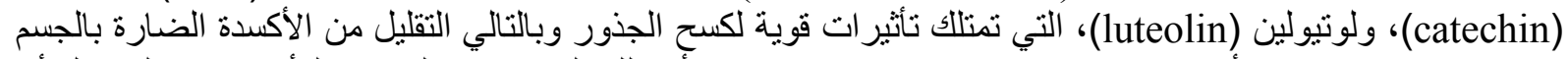

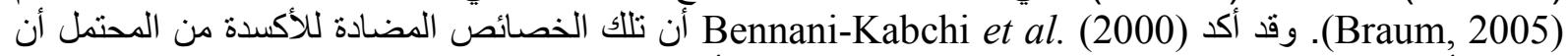

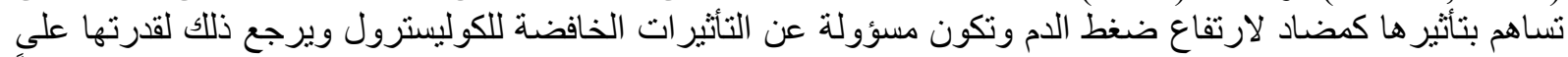

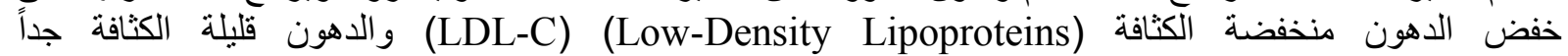
Al-qarawi et al. (2002) وقان أن الخداصة (VLDL-C) (Very Low-Density Lipoproteins)

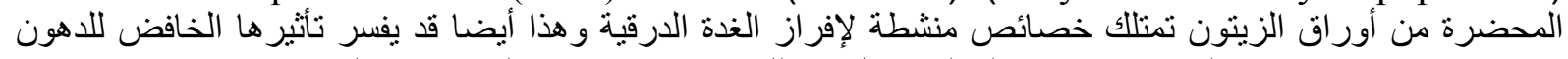

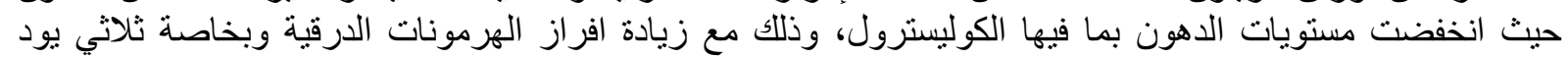

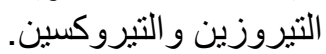

\section{الاستنتاجات و التوصيات}

ا ـ نستتنج مما سبق امكانية استخدام الخلاصة الكحولية لأوراق الزينون كعقار دوائي ذو منشأ نباتي يلعب دور ا فعالاً في

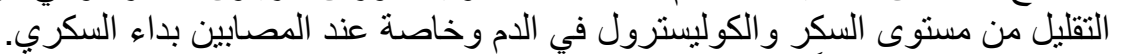

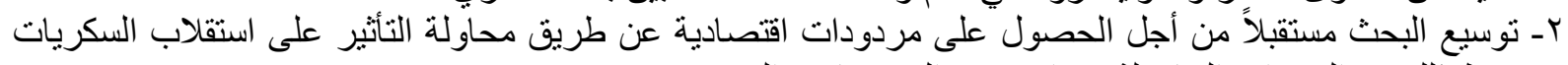
وربط ذللك مع التغير ات الحاصلة في أستل الحقلاب البروتينات و الدهون.

\section{المراجع}

الكاكي، إسعاعيل صالح (999 19): أثثير بعض النباتات المخفضة لسكر الدم في بيروكسيدة الدهن ومستوى الكلوتاثيون

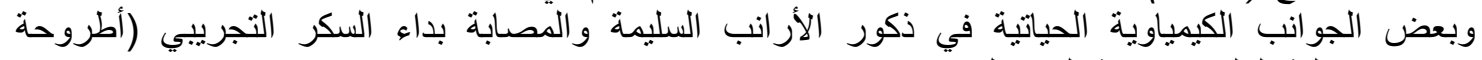

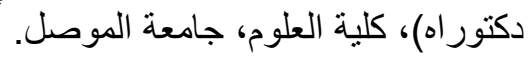
الزبيدي، زهير نجبي؛؛ بيان، هدى عبد الكريج؛ فليح، فارس كاظم (1997 1): دليل العلاج بالأعشاب الطبية العر اقية. شركة

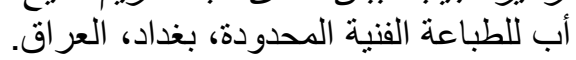

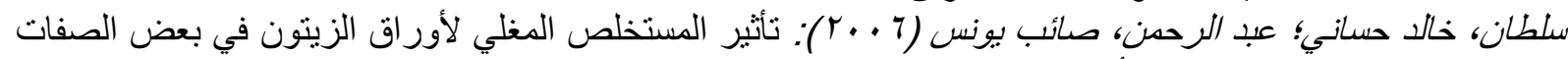

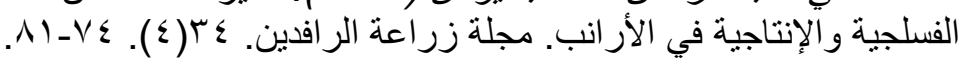

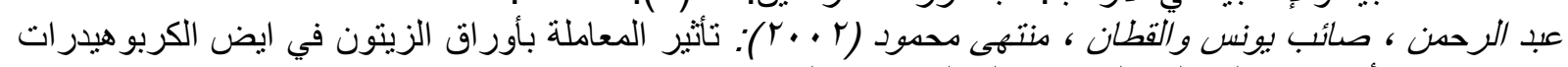

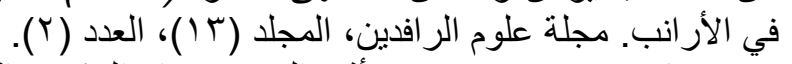

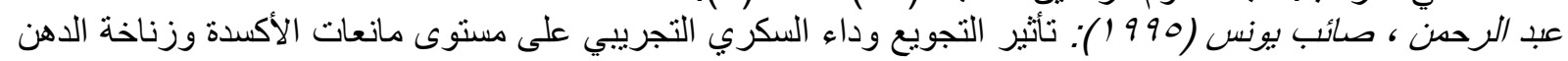

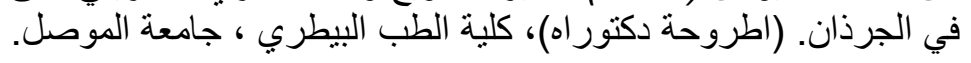

\section{REFERENCES}

Al-azzawie, H.S. and Alhamdani, M.S. (2005): Hypoglycemic and antioxidant effect of oleuropein in alloxan-diabetic rabbits. Life sciences. 78: 1371-1377.

Al-hussary, N. (1993): Effect of Fenugreek seeds decoction on blood glucose, cholesterol and triglycerides levels in normal and alloxan diabetic rabbits. Iraqi Journal Veterinary medicine. 1(6): 102-105.

Al-qarawi, A.A.; Aldamegh, M.A. and Elmougy, S.A. (2002): Effect of freeze dried extract of olea europaea on the pituitary-thyroid axis in rats. Phytother. Res. 16: 286-287.

Ananthan, R.; Latha, M.; Ramakumar, K.M.; Pari, L. and Narmatha, B. (2003): Effect of Gymnema montanum leaves on serum and tissue lipids in alloxan diabetic rats, 4: 183-189. 
Andreadou, I.; Iliodromitis, E.K.; Mikros, E.; Constantinou, M.; Agalias, A.; Magiatis, P.; Skaltsounis, A.L.; Kamber, E.; Tsantili-Kakoulidou, A. and Th Kremastinos, D. (2006): The Olive Constituent Oleuropein Exhibits Anti-Ischemic, Antioxidative, and Hypolipidemic Effects in Anesthetized Rabbits. J. Nutr., 136: 2213-2219.

Alarcon-Aguilar, F.J.; Roman-Ramos, R.; Flores-Saenz, J.L. and Aguirre-Garcia, F. (2002): Investigation on the hypoglycaemic effects of extracts of four Mexican medicinal plants in normal and alloxan-diabetic mice. Phytother Res., 16: 383-386.

Bennani-Kabchi, N.; Fdhil, H.; Cherrah, Y.; El Bouayadi, F.; Kehel, L. and Marquie, G. (2000): Therapeutic effect of Olea europea var oleaster leaves on carbohydrate and lipid metabolism in obese and prediabetic sand rats Psammomys obesus. Ann. Pharm. 58: 271-277.

Benavente-Garcia, O.; Castillo, J.; Lorente, J.; Ortuno, A. and Del Rio, J.A. (2000): Antioxidant activity of phenolics extracted from Olea europaea L. leaves. Food Chem. 68: 457-462.

Braun, L. (2005): Olive-leaf extract. The Journal of Complemantary Medicine. p: 69-73.

Briante, R.; Patumi, M.; Terenziani, S.; Bismuto, E.; Febbraio, F. and Nucci, R. (2002): Olea europaea L. leaf extract and derivatives: antioxidant properties. J. Agric. Food Chem. 50: 4934-4940.

Brown, D. (2001): Encyclopedia of herbs dorling. Kindersley limited, 294-295.

Cheij, R. (1984): McDonald Encyclopedia of Medical plants. McDonald and Co., (publishers) Ltd, London, pp.: 209: 309-313.

Dekanski, D.; Janicijevic-Hudomal, S.; Tadic, V.; Markovic, G.; Arsic, I. and Mitrovic, D.M. (2009): Phytochemical analysis and gastroprotective activity of an olive leaf extract. Serb. Chem. Soc., 74 (4): 367-377.

Deshmuk, S. and Brole, M. (1975): Studies on insecticidal properties of indigenous plant products .G. Ethropharmacol. 37: 11-18.

Dimitrova, S.S.; Georgive, I.P.; Kanelov, I.N.; Iliev, Y.I. and Taner, S.I. (2008): Intravenous glucose tolerance test and glucose pharmacokinetic in rabbits. Bulg. J. Vet. Med. 11(3): 161-169.

Dubey, G.P.; Dixit, S.P. and Alok, S. (1994): Alloxan-induced Diabetes in Rabbits and Effect of a Herbal Formulation D-400 Indian Journal of Pharmacology. (26): 225-226.

Eidi, A.; Eidi, M. and Darzil, R. (2009): Antidiabetic Effect of Olea europaea L. in Normal and Diabetic Rats Phytother. Res., 23: 347-350.

Etuk, E.U. (2010): Animals models for studying diabetes mellitus. Agric. Biol. J.N. Am. 1(2): 130-134.

Fehri, B.; Aiache, J.M.; Memmi, A.; Korbi, S.; Yacoubi, M.T.; Mad, S. and Lamasion, J.L. (1994): Hypotension, hypoglycemia and hypouricemia recorded after repeated administration of aqueous leaf extract of Olea europaea L. J. Pharm-Belg. 49(2): 101-108.

Geo, T.; Grossberg, M.D. and Fox, B. (2007): The essential herb-drug-vitamin interaction guide, 355-356.

Gonzalez, M.; Zarzuelo, A.; Gamez, M.J.; Utrilla, M.P.; Jimenez, J. and Osuna, I. (1992): Hypoglyceamic activity of olive leaf. Planta Med. 58: 313-315.

Hashemi, M.; Dostar, Y.; Rohani, S.R.; Azizi Saraji, A.R. and Bayat, M. (2009): Influence of Aloxanes on the Apoptosis of Pancreas B-Cells of Rat. World Journal of Medical Sciences. 4(2): 70-73.

Jemai, H.; El-Feki, A. and Sayadi, S. (2009): Antidiabetic and antioxidant effects of hydroxytyrosol and oleuropein from olive leaves in alloxan-diabetic rats. J. Agric Food Chem., 57(19): 8798-804.

Jouad, H.; Haloui, M.; Rhiouani, H.; El Hilaly, J. and Eddouks. M. (2001): Ethnobotanical survey of medicinal plants used for the treatment of diabetes, cardiac and renal 
diseases in the North Center Region of Morocco (fez-Boulemane). J Ethnopharmacol. 77: 175-182.

Kamtchouing, P.; Kahpui, S.M.; Djomeni, P.D.; T'edong, L.; Asongalem, E.A. and Dimoa, T. (2006): Anti-diabetic activity of methanol methylene chloride stem bark extracts of Terminalia superba and Canarium schweinfurthii on streptozotocin-induced diabetic rats. J. Ethnopharmacol., 104: 306-309.

Katsumata, K. and Katsumata, Y. (1990): The potentiating effect of the simultaneous administration of tolbutamide, glibenclamide, and gliclazide on the development of alloxan - induced diabetes in rats. Hom. Metab .Res, 22: 51-52.

Khudiar, K.K. (2000): The role of aqueous extract of olive (Olea europaea) leaves and garlic (Allium sativum) in a meliorating the effects of experimentally induced atherosclerosis in rats. PH.D. Thesis, College of veterinary medicine. University of Baghdad.

Lalas, S.; Athanasiadis, V.; Gortzi, O.; Bounitsi, M.; Giovanoudis, I.; Tasknis, J. and Bogiatzis, F. (2011): Enrichment of table olives with polyphenols extracted from olive leaves. Food Chemistry. 127: 1521-1525.

Lenich, A.C.; Hobanian, A.V.; Brecher, P. and Zannis, V.I. (1990): Effect of dietary cholesterol and alloxan diabetes on tissue cholesterol and apo lipoprotein E m RNA levels in rabbit. J. lipids Res. 32 (3): 432-438.

Lenzen, S.; Brunig, H. and Munster, W. (1992): Effect of alloxan and ninhydrin on mitochondrial $\mathrm{Ca}+2$ transport .Mol. Cell. Biochem, 118: 141-151.

Maechler, P.; Wolheim, C.B.; Bentzen, C.L. and Niesor, E. (1993): Importace of exogenous cholesterol in diabetic rats: effect of treatment with insulin or with an acyl- COA: cholesterol acyl transferas inhibition. Ann. Nutr. Metab. 37 (4): 199-209.

Mahesar, H.; Bhutto, M.A.; Khand, A.A. and Narejo, N.T. (2010): Garlic used as an alternative medicine to control diabetic mellitus in alloxan-induced male rabbits. Pak. J. Physiol. 6(1): 39-41.

Montvale, N.J. (2000): Physician's desk references for herbal medicine. Medical economics company, p.556.

Okamoto, H. (1985): Molecular basis of experimental diabetes: Degeneration, oncogenesis and regeneration of pancreatic $\beta$-cells of islet of Langerhans. BioEssay. 2: 15-21.

Omar, S.H. (2010): Oleuropein in olive and its pharmacological effects. Sci. Pharm., 78: 133-154.

Park, B.; Rho, H.; Park, J.; Cho, C.; Kim, J.; Chung, H. and Kim, H. (1995): Protective mechanism of glucose against alloxan-induced pancreatic $\beta$-cells damage. Biochem Biophys Res. Commun. 210: 1-6.

Petit, P.; Sauvarie, Y.; Ponsin, G.; Manteghetti, M.; Fave, A. and Ribes, G. (1993): Effect of a fenugreek seed extract on feeding bahaviour in rat: Metabolic - indocrine correlates Pharmacol. Biochem. Behav., 45: 369-374.

Prince, D.S.; Kamalakkannan, N. and Menon, V.P. (2004): Antidiabetic and antihyperlipidemic effect of alcoholic extract of Syzigium cumin seeds in alloxan induced diabetic albino rats. J. Ethnopharmacol. 91(203): 209-213.

Radhika, R.; Kumari, K. and Sudarsanam, D. (2010): Antidiabetic activity of Rheum emodi in Alloxan induced diabetic rats. International Journal of Pharma Sciences and Research (IJPSR). 1(8): 296-300.

Rao, B.K.; Kesarulu, M.M.; Giri, R. and Apparao, C. (1999): Antidiabetic and hypolipidemic effects of Momordicacymbalaria Hook fruit power in alloxan diabetic rats. J, Ethnopharmacol. 67(1): 103-109.

Sauvaire, Y.; Baissac, Y.; Leconte, O.; Petit, P. and Ribes, G. (1996): Steroid saponins from fenugreek and some of their biological properties. Adv. Exp. Med. Biol. 405: 37-46. 
Said, O.; Fulder, S.; Khalil, K.; Azaizeh, H.; Kassis, E. and Saad, B. (2008): Maintaining a physiological blood glucose level with 'glucolevel', a combination of four antidiabetes plants used in the traditional arab herbal medicine. ECAM. 5(4): 421-428.

Schoenfelder, T.; Cirimbelli, T.M. and Citadini-Zanette, V. (2006): Acute effect of Trema micrantha on serum glucose levels in normal and diabetic rats. J. Ethnopharmacol. 107: 456-459.

Sharma, S.B.; Nasir, A.; Probhu, K.M.; Murthy, P.S. and Dev, G. (2003): Hypoglycemic and hypolipidemic effect of ethanolic extract of seed of Eugenia jambolana in alloxan induced diabetic rabbits. J. Ethnopharmacol. 85 (2-3): 201-206.

Satoa, H.; Genetb, C.; Strehlea, A.; Thomasa, C.; Lobsteinc, A.; Wagnerb, A.; Mioskowskib, C.; Auwerxa, J. and Saladind, R. (2007): Anti-hyperglycemic activity of a TGR5 agonist isolated from Olea europaea Biochemical and Biophysical Research Communications. 362(4): 793-798.

Szkudelski, T. (2001): The mechanism of alloxan and streptozotocin action in Bcells of the rats pancrease. Physiol. Res. 50: 536-546.

Takasu, N.; Aswan, T.; Komiya, I.; Nagasawa, Y. and Yamada, T. (1991): Alloxan-induced DNA strand breaks in pancreatic islets, evidence for $\mathrm{H} 2 \mathrm{O} 2$ as an intermediate. Biol.Chem. 266(4): 2112-2114.

Tiedge, M.; Lortz, S.; Drinkgren, J. and Lenzen, S. (1997): Relation between antioxidant enzyme gene expression and antioxidative defense status of insulin producing cells. Diabetes. 46: 1733-1742.

Trichopoulou, A.; Kouris-Blazos, A.; Wahlqvist, M.L.; Gnardellis, C.; Lagiou, P.; Polychronopoulos, E.; Vassilakou, T.; Lipworth, L. and Trichopoulos, D. (1995): Diet and overall survival in elderly people. British medical journal. 311: 1457-1460.

Tshikalange, T.E.; Meyer, J.J. and Hussein, A.A. (2005): Antimicrobial activity,toxicity and the isolation of a bioactive compound from plants used to treat sexuallay transmitted disease. J. Ethnopharmacol. 96 (3): 515-9.

Verspohl, E.J. (2002): Recommended testing in diabetes research. Planta Med., 68: 581-590.

Wilson, G.L.; Patton, N.J.; McCord, J.M.; Mullins, D.W. and Mossman, B.T. (1984): Mechanisms of streptozotocin and alloxan - induced damage in rat B cells. Dialetologies. 27 (6): 587- 591.

Wunwisa, K. and Areeya, K. (2005): Antimicrobial properties of the traditional flower vegetable extracts. Au J.T. 2: 71-74. 
Assiut Vet. Med. J. Vol. 58 No. 133 April 2012 